\title{
A Coordinated, Risk-Based, National Forest Biosecurity Surveillance Program for Australian Forests
}

\author{
Angus J. Carnegie ${ }^{1,2 *}$, Francisco Tovar $^{3}$, Susie Collins ${ }^{4}$, Simon A. Lawson ${ }^{5}$ and \\ Helen F. Nahrung 5 \\ ${ }^{1}$ Forest Science, Department of Primary Industries, Parramatta, NSW, Australia, ${ }^{2}$ School of Environment Science \\ and Engineering, Southern Cross University, Lismore, NSW, Australia, ${ }^{3}$ Plant Health Australia, Bunbury, WA, Australia, \\ ${ }^{4}$ Department of Agriculture, Water and the Environment, Canberra, ACT, Australia, ${ }^{5}$ Forest Research Institute, University \\ of the Sunshine Coast, Maroochydore, QLD, Australia
}

\section{OPEN ACCESS}

Edited by:

Manuela Branco,

University of Lisbon, Portugal

Reviewed by:

Nicolas Meurisse,

New Zealand Forest Research Institute Limited (Scion), New Zealand

Trudy Paap,

University of Pretoria, South Africa

*Correspondence:

Angus J. Carnegie

angus.carnegie@dpi.nsw.gov.au

Specialty section:

This article was submitted to

Pests, Pathogens and Invasions,

a section of the journal

Frontiers in Forests and Global

Change

Received: 11 August 2021

Accepted: 10 December 2021

Published: 05 January 2022

Citation:

Carnegie AJ, Tovar F, Collins $S$,

Lawson SA and Nahrung HF (2022) $A$

Coordinated, Risk-Based, National

Forest Biosecurity Surveillance

Program for Australian Forests.

Front. For. Glob. Change 4:756885.

doi: 10.3389/ffgc.2021.756885
Australia has a comprehensive plant biosecurity system, with the Australian Government responsible for pre-border (e.g., off-shore compliance) and border (e.g., import inspections) activities, while state governments undertake a variety of post-border activities (e.g., post-border surveillance, management of pest incursions, and regulation of pests) designed to reduce alien pest and pathogen arrival and establishment. Once an alien pest or pathogen has established and spread, its management becomes the responsibility of the land manager. There has been a growing understanding among plant industries of the need to be more engaged in post-border biosecurity activities, including resourcing and undertaking early detection surveillance and contingency planning. Here we summarize Australia's broader plant biosecurity system along with current forest-specific biosecurity surveillance activities. We describe the development of a proposed forest biosecurity partnership between the Australian Government, state governments and the forest sector to establish a post-border, risk-based National Forest Pest Surveillance Program. We outline why there is a recognized need for such a program, how it would improve biosecurity outcomes in relation to forests, its component activities, and key stakeholders and beneficiaries.

\section{Keywords: biosecurity, invasive species, stakeholder engagement, post-border surveillance, collaboration, pests} and diseases

\section{INTRODUCTION}

Australia has a wide range of forest resources including plantation, amenity and native forests that require protection from exotic biosecurity threats. Seventeen percent (134 million hectares) of Australia's land area is covered by forests, which are highly valued ecologically, economically, and culturally (Montreal Process Implementation Group for Australia and National Forest Inventory Steering Committee, 2018). These forests provide significant provisioning (food, fiber, materials, biodiversity), regulating (climate, soils, water), and cultural (culture, spiritual, beauty) services (Carnegie et al., 2021). In addition, amenity trees form a major component of urban green spaces, providing multiple benefits such as improving physical and mental health, increasing urban biodiversity, and mitigating the urban heat-island effect (FAO, 2016).

The forest, wood and paper products industry is a significant contributor to the Australian economy, ranking as the eighth largest manufacturing sector, and with gross value of sales in excess of AU $\$ 23$ billion and an industry value-add of AU $\$ 9$ billion (ABARES, 2016, 2017). As an individual sector, this ranks higher than the gross value of production of the horticulture sector 
(vegetables, fruit, nuts) at AU\$8.3 billion, wheat (AU\$6.2 billion), and cattle (AU\$13.1 billion) (ABARES, 2017). Additionally, the forest industry directly employs over 67,000 people (ABARES, 2017), with many of these jobs based in rural and regional Australia. Hence, there is considerable incentive to safeguard the industry from alien pest and pathogen threats.

Several reviews on forest biosecurity have been carried out in recent years identifying significant gaps in Australia's onshore, post-border forest biosecurity systems (Mohammed et al., 2011; Carnegie et al., 2017, 2018a; Tovar et al., 2017). Cumulatively, outputs from these reviews highlighted the importance of developing a National Forest Biosecurity Surveillance Strategy (NFBSS) (Department of Agriculture and Water Resources, 2018a,b). Here we provide some historical context to these reviews, the development of the NFBSS and outline the current proposal to improve forest biosecurity arrangements in Australia into the future.

\section{Australia's Forests}

Australia's 134 million ha of forests, the 7th largest forest estate in the world, are dominated by eucalypts (Eucalyptus, Corymbia and Angophora; 101 million ha), Acacia (11 million ha), and Melaleuca (6 million ha), with smaller areas of rainforest (3.5 million ha) and other forest types (Montreal Process Implementation Group for Australia and National Forest Inventory Steering Committee, 2018). These forests are primarily restricted to the coastal zones in Australia, with woodlands extending into drier interior zones. Five million hectares of multi-use public native forest is available and suitable for commercial wood production, though less than 80,000 ha is harvested each year. There are also 2 million ha of plantations, primarily comprising Pinus, Eucalyptus, and Araucaria, the majority of which are privately owned. The softwood plantation estate, dominated by Pinus radiata, $P$. elliottii, and $P$. elliottii $\times P$. caribaea hybrids, expanded rapidly from the 1960s, reaching a plateau of 1 million ha in the 1990s. The hardwood plantation estate (Eucalyptus and Corymbia species) rapidly expanded from the 1990s and has also plateaued at 1 million ha. In addition, a wide range of native and exotic genera have been planted as amenity trees in urban and peri-urban areas (Burley et al., 2019; Bennett, 2020; Nahrung and Carnegie, 2020), with key taxa including Eucalyptus, Pinus, Platanus, Populus, Quercus, and Ulmus. Urban and peri-urban trees can act as bridgeheads for the establishment and spread of invasive forest species (Paap et al., 2017; Branco et al., 2019), and thus can be used as sentinels for early detection of invasive alien species (Smith et al., 2010; Paap et al., 2017; Mansfield et al., 2019).

\section{Alien Pests and Pathogens of Forests and Their Impact in Australia}

More than 260 species of alien forest insect pests and pathogens (hereafter, "pests") have established in Australia since 1885, with over a third impacting other industries such as horticulture and agriculture (Nahrung and Carnegie, 2020). The majority (87\%) of the established alien pests are associated with non-native hosts (e.g., Pinus, Platanus, Populus, Quercus, Ulmus); those on native hosts are primarily polyphagous species. About $40 \%$ of these alien pests were largely cosmopolitan at the time of introduction in Australia, another third were of European or Asian origin, and the remainder originated from other continents. Most (80\%) established alien pests have spread to multiple Australian states since initial detections. Eighteen percent of established alien pests cause moderate-to-high impact, with $28 \%$ of alien pests considered primarily forestry species causing moderateto-high impact (Nahrung and Carnegie, 2020). High impact alien pests include: Sirex noctilio, Dothistroma septosporum, Essigella californica, Ips grandicollis/Ophiostoma ips, and Diplodia sapinea of Pinus plantations; Phytophthora cinnamomi and Austropuccinia psidii of native forests; Lepteutypa cupressi and Xanthogaleruca luteola of amenity trees; and Hylotrupes bajulus and Serpula lacrymans of timber-in-service.

Most of these established alien pests were not detected early enough to attempt eradication or were not deemed a significant enough pest to warrant an eradication attempt-with only four eradication attempts (and only one successful) in the past 20 years (Carnegie and Nahrung, 2019)-emphasizing the need for early detection of arriving alien pests.

\section{AUSTRALIA'S PLANT BIOSECURITY SYSTEM}

Biosecurity involves the mitigation of exotic pest risks that may be potentially damaging through impacts on the economy, the environment, and society. In Australia, this involves legislation, regulatory processes and management activities along a biosecurity continuum from the pre-border, at the border and post-border (Beale et al., 2008; Figure 1). These are all designed, in the first instance, to reduce the risk of alien pests from entering or establishing in Australia. Failing this, biosecurity also involves the minimization, where practicable, of the subsequent spread of alien pests.

The Australian Government's Department of Agriculture, Water and the Environment (DAWE) is the lead agency responsible for biosecurity [the National Plant Protection Organisation representing Australia at the International Plant Protection Convention (IPPC)], working offshore (i.e., preborder) and at the border. It is also responsible for managing Australia's international phytosanitary obligations under the IPPC. State governments, along with DAWE, are primarily responsible for post-border biosecurity measures, with industry and other stakeholders recently increasing their involvement under the "shared responsibility" paradigm (Nairn et al., 1996). If pest mitigation measures fail and a pest becomes established, its management becomes the responsibility of the land manager.

\section{Framework for Managing Plant Biosecurity}

The framework for managing the cooperative partnership for delivering an effective plant biosecurity system is built on a range of strategies, policies and legislation, such as the Biosecurity Act 2015 (Australian Government, 2015), Intergovernmental 


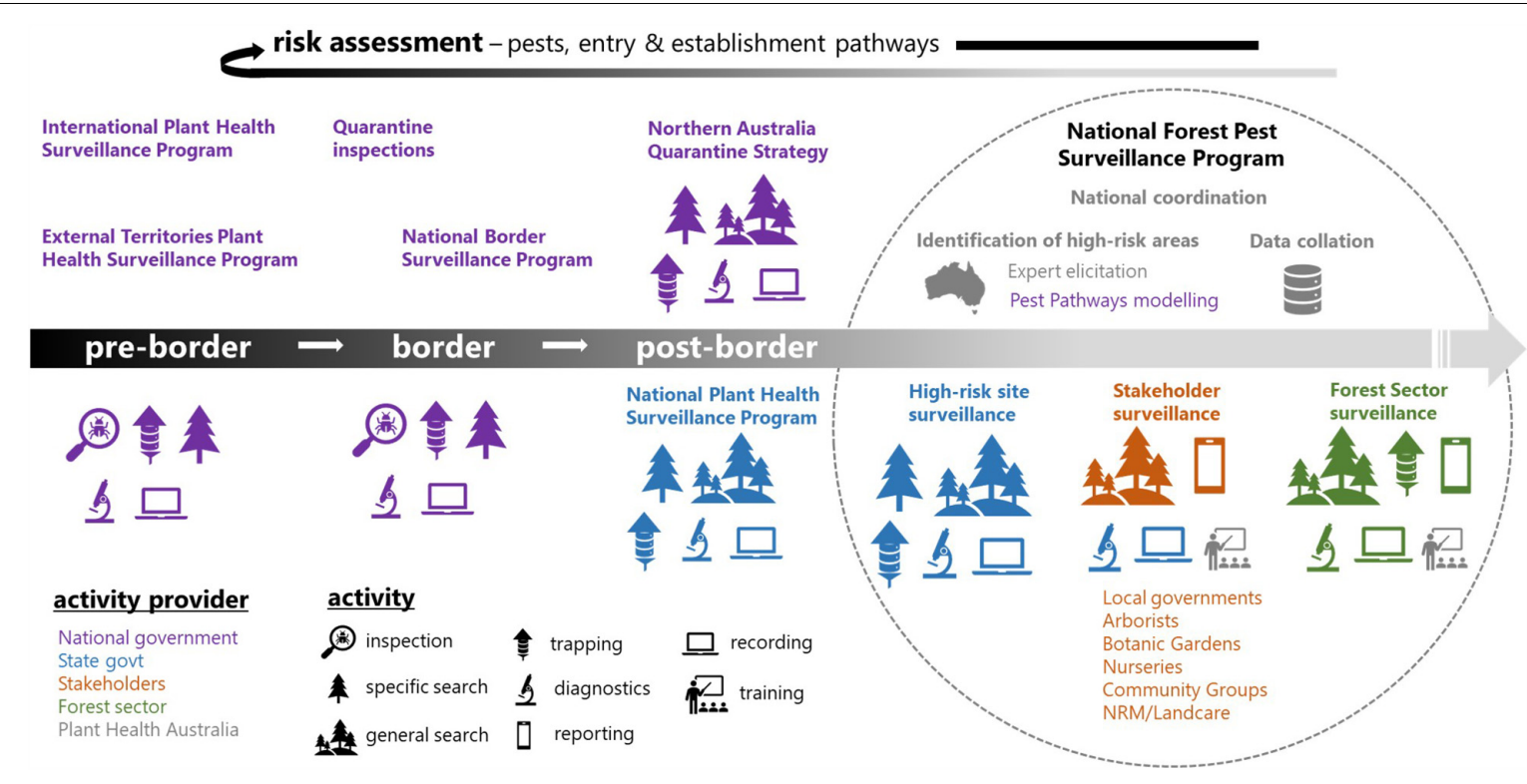

FIGURE 1 | Surveillance activities and providers across the Australian biosecurity continuum with the addition of the National Forest Pest Surveillance Program (NFPSP). The Australian Government inspects vessels, planes, travelers, and commodities both pre-border and at the border. Specific and general surveillance post-border is also undertaken but delivered by the Australian Government (e.g., Northern Australia Quarantine Strategy) or state governments (e.g., National Plant Health Surveillance Program). Where appropriate, trapping is undertaken. Diagnostics are delivered through national or state government laboratories (private laboratories occasionally). All service providers record surveillance activities. The NFPSP will support identification of areas of highest risk for exotic forest pest entry and provide national coordination, through Plant Health Australia, of post-border surveillance activities delivered by state governments, collaborating stakeholders or the forest sector. It will include collation of national data, including relevant data from other national or state government programs. Training to build national capacity will also occur.

Agreement on Biosecurity (Council of Australian Governments, 2019) and the National Plant Biosecurity Strategy (Plant Health Australia, 2010). These provide details about the current structure and a vision of how a future plant biosecurity system should operate. Australia's biosecurity arrangements aim to reduce biosecurity risk to a very low level but not to zero. This definition (an "acceptable level of protection") reflects community expectations while recognizing that zero risk is not feasible (Craik et al., 2017; Council of Australian Governments, 2019), and draws a balance between protecting Australia from alien pests and maintaining international trade obligations. Biosecurity is strongly considered as a shared responsibility between governments, industry and individuals (Commonwealth of Australia, 2021).

Australia's biosecurity system has been subject to several reviews in recent times (Craik et al., 2017; Inspector-General of Biosecurity, 2019a), including a Senate enquiry into environmental biosecurity (Department of Agriculture and Department of Environment, 2014), with the recommendations recognizing that a future-focused approach is vital for maintaining a strong and resilient biosecurity system that will protect Australia from new challenges. As a result, there is a continuous improvement by industry and governments to Australia's plant biosecurity system (Plant Health Australia, 2021), with the key themes including: risk-based management across the biosecurity continuum; shared responsibility; and ensuring capacity and capability in biosecurity expertise. Similarly, the need for continual improvement in plant biosecurity has been recognized in other countries (Magarey et al., 2009; Dyck and Hickling, 2021).

\section{Emergency Plant Pest Response Deed}

A fundamental component of the Australian plant biosecurity system is the Emergency Plant Pest Response Deed (EPPRD), which is an agreement between the national and state governments, 38 plant industries (including the Australian Forests Products Association) and Plant Health Australia (collectively known as the signatories), that provides directions on rapid, collaborative and efficient response to alien plant pest incursions (Plant Health Australia, 2020). The EPPRD is a legally binding document that outlines the basic operating principles and guidelines for eradication responses following the detection and declaration of an Emergency Plant Pest (EPP). The EPPRD provides a national response management structure that enables all governments and plant industry signatories affected by the EPP to contribute to decision-making during a response, via the Consultative Committee on Emergency Plant Pests, with the National Management Group the final arbiter of decisions on whether a national eradication response is required. A key component of the EPPRD is an agreed structure for the sharing of costs to deliver eradication responses: costs are divided between signatories affected by the EPP based on the relative potential impact of the EPP. The EPPRD also includes a mechanism to reimburse growers whose crops or property are directly damaged or destroyed through implementing an EPP response. Response actions to an EPP are guided by PLANTPLAN, a part of the 
EPPRD that describes Australia's technical response plan for EPP incursions (Plant Health Australia, 2019a,b).

Plant Health Australia (PHA) is the custodian and national coordinator of the government-industry EPPRD partnership for plant biosecurity in Australia and is funded from annual subscriptions paid by members (i.e., signatories to the EPPRD). Through PHA, current and future needs of the plant biosecurity system can be mutually agreed, issues identified, and solutions to problems found. PHA's independence and impartiality allow the company to put the interests of the plant biosecurity system first and support a longer-term perspective.

\section{National Environmental Biosecurity Response Agreement}

The National Environmental Biosecurity Response Agreement (NEBRA) was signed in 2012 as a formal agreement between the national and state governments providing response guidelines, including cost-sharing arrangements, for significant alien pest incursions predominantly impacting the environment or public amenity assets (Craik et al., 2017). DAWE is the custodian of NEBRA, and response decisions are made through a National Biosecurity Management Consultative Committee convened in response to pest incursions to provide technical and expert advice to the National Management Group for decisions on whether a national eradication response is required.

\section{Forest-Specific Biosecurity Initiatives}

Forest biosecurity forms part of Australia's overarching plant biosecurity system. Alien forest pests can enter Australia via numerous commercial (e.g., cargo, live plants) and noncommercial (e.g., passenger baggage, mail) pathways. Alien forest pests are monitored offshore and at the border, but postborder surveillance for alien forest pests is less structured and poorly resourced. The Australian Forests Products Association (AFPA) is the national industry body that represents the biosecurity interests of the plantation timber industry. AFPA is the forest industry's signatory to the EPPRD, and currently contribute $\$ 0.005 / \mathrm{m}^{3}$ of production to PHA's biosecurity levy, with additional contribution through the EPPRD cost-sharing agreement in the event of an incursion. AFPA's responsibilities for biosecurity include planning and implementation, liaising with the Australian and state governments on trade issues, and funding and supporting biosecurity initiatives, and participating in emergency response processes for relevant alien pest incursions.

A Plantation Forest Biosecurity Plan has been developed in partnership with the forest industry and government (Plant Health Australia, 2007, 2013, 2021), outlining key threats to the industry, risk mitigation plans, identification and categorization of alien pests and contingency plans. A Biosecurity Manual for the Plantation Timber Industry has also been produced, which provides an overview of biosecurity, fact sheets on key threats, plantation monitoring and surveillance advice, and reporting requirements (Plant Health Australia, 2015).

Just prior to the detection of myrtle rust (Austropuccinia psidii) in Australia in 2010 (Carnegie et al., 2010), the forest sector through its research and development corporation, Forest and Wood Products Australia (FWPA), commissioned an audit of Australia's biosecurity arrangements in relation to alien forest pests (Mohammed et al., 2011) and a subsequent Research, Development and Extension investment plan in Forest Biosecurity and Preparedness (Bailey, 2012). The audit process, a questionnaire and a national workshop of technical experts, industry and government, highlighted multiple issues, including: a decline in forest health expertise and capacity; lack of investment in surveillance and diagnostics; lack of adequate training and/or biosecurity awareness across forest stakeholders; delays in implementing emergency responses; the agri-centric nature of state and national biosecurity agencies; and the resulting fragmented communication and coordination between forest health specialists, the forest sector and biosecurity agencies, compared to agriculture and horticulture (Mohammed et al., 2011). Key recommendations from the audit included the need for additional investments to improve forest biosecurity capacity and capability, the formation of a national body of forest health and industry experts to represent the forest sector in matters of forest biosecurity, ${ }^{1}$ inclusive of a dedicated biosecurity officer ${ }^{2}$ (Mohammed et al., 2011).

Both Mohammed et al. (2011) and Bailey (2012) highlighted the need to demonstrate the benefits of industry investment in biosecurity and the potential costs of non-participation. In response, Carnegie et al. (2017) evaluated the costs and benefits of managing new and existing biosecurity threats to Australia's plantation industry (Cameron et al., 2018; Carnegie et al., 2018a,b; Lawson et al., 2018). Trade and interception data for Australia demonstrates that there is a clear and increasing risk of alien forest pests reaching Australia-imports of pest host commodities (wood products, wood packaging material, containers) has grown rapidly and interception of forest pests at the border has increased (Lawson et al., 2018). While forest pests are adequately dealt with by biosecurity measures preborder and at the border (for example, termites were the third most-intercepted priority plant pest at the border during 20122017; Inspector-General of Biosecurity, 2019b), there are gaps in post-border forest biosecurity activities, due to the agricentric nature of state biosecurity agencies, and an historical reluctance by the forest industry to engage in biosecurity (Mohammed et al., 2011; Carnegie et al., 2017). Alien pests have already caused significant economic impact to forest plantations (Cameron et al., 2018), as well as amenity forests and native ecosystems (Cahill et al., 2008; Carnegie and Pegg, 2018; Nahrung and Carnegie, 2020). Carnegie et al. (2018b) demonstrated the financial benefits of biosecurity activities in lowering the risk of further alien pests establishing in Australia; for example, it would be economically efficient to spend up to AU \$345,000 pa to keep a single pest (pine wilt nematode) out of Queensland alone. Dodd et al. (2020) estimated the net present value of Australia's biosecurity system to average a return on investment of 30:1.

\footnotetext{
${ }^{1}$ The Forest Health and Biosecurity subcommittee of the Australian Forest Products Association now fulfills this role.

${ }^{2}$ A National Forest Biosecurity Coordinator has been established.
} 


\section{DEVELOPING A NATIONALLY COORDINATED APPROACH TO FOREST BIOSECURITY}

\section{Incursions as Call to Action}

The detection in coastal New South Wales of myrtle rust (Austropuccinia psidii) in 2010 (Carnegie et al., 2010; Carnegie and Pegg, 2018) — at the time Australia's number one high priority alien pest-served as a warning to forest stakeholders that despite Australia's strong biosecurity system pests can and do circumvent biosecurity arrangements. NEBRA was not ratified when myrtle rust was detected, and the forest industry was not a signatory to the EPPRD and as such had no formal say in the emergency response. This was partly the impetus for AFPA signing up to the EPPRD in 2013. The detection in 2014 and subsequent eradication attempt of giant pine scale (Marchelina hellenica) in Victoria and South Australia (Carnegie and Nahrung, 2019; Agriculture Victoria, 2021), was the first cost-shared response since the forest industry signed the EPPRD. The eradication attempt was unsuccessful, at a direct cost to industry of more than AU\$2.2 million (Carnegie and Nahrung, 2019), in part because the pest was not detected early enough, and tree destruction was not considered socially acceptable; further strengthening the case for the forest industry to ensure adequate forest biosecurity systems are in place (Carnegie et al., 2019).

\section{Plant Biosecurity Surveillance}

National plant biosecurity surveillance programs in Australia need to target a broad range of pests from many plant industries. Australian Government funded and coordinated surveillance (Figure 1) such as the National Border Surveillance (NBS) program and the National Plant Health Surveillance Program (NPHSP) target only a few forest pests. The NBS program is conducted by DAWE and focuses on areas in the vicinity of international ports and import facilities. It only includes a small number of alien forest pests such as Japanese pine sawyer beetle (Monochamus alternatus). The NPHSP, conducted by state agencies, focuses mainly on areas surrounding import pathways and high-risk areas within urban and peri-urban areas surrounding major international ports. A few alien forest pest species, including gypsy moth (Lymantria dispar), are targeted under this program. The federal government, through the Northern Australia Quarantine Strategy (NAQS), also conducts a combination of targeted and general biosecurity activities across Australia's north. NAQS targets pests focused on tropical plant species, informed by pre-border alerts of new pests emerging in countries to Australia's north which may arrive via human-mediated or natural pathways. Alien forest pests are not specifically targeted by NAQS although there are forest-relevant taxa on their surveillance list, including emerald ash borer (Agrilus planipennis) and the black twig borer (Xylosandrus compactus).

\section{Forest-Specific Biosecurity Surveillance}

There is currently no national forest-specific biosecurity surveillance program in Australia. In the early 2000s, pilot high-risk site surveillance (HRSS) projects focusing on alien forest pests were initiated by forest biosecurity technical experts in Queensland and Tasmania to assess the benefits and feasibility of this approach (Bashford, 2003; Wylie et al., 2008). These programs, primarily focused on insect trapping, continued in Queensland until 2006 and in Tasmania until 2011 (Wylie et al., 2008; Bashford, 2012). In Queensland, insect trapping for forest pests was transferred to the NPHSP until 2019, with Asian gypsy moth now the only taxa included. In Victoria, a separate program, focused on sentinel trees, was initiated in the late 2000s, utilizing the location of import facilities and local council tree databases to assist in identifying risk sites for potential establishment of alien pest incursions (Smith et al., 2010). This surveillance of sentinel trees was primarily pest-specific [e.g., Dutch elm disease (Ophiostoma novo-ulmi) surveys of Ulmus]. Victoria has, however, conducted insect trapping for alien forest pests as part of the NPHSP for more than a decade. In New South Wales, an alien forest pest surveillance program was initiated in 2014 that focuses on insect trapping, sentinel tree surveillance and stakeholder engagement in the vicinity of entry ports (Carnegie et al., 2018c). This program will continue through to 2022, funded by a single forest grower.

Forest health surveillance (FHS) is funded by individual growers in Australia (Carnegie et al., 2017, 2018a), but is an integral part of an overall forest biosecurity program (Tovar et al., 2017). While the primary aim of FHS is the detection and mapping of damage agents (e.g., pests, diseases, climatic disorders), there are multiple aspects that directly benefit biosecurity. FHS is vital for confirming the distribution of current endemic and established alien pest species and provides essential information for confirming pest free status, which is important for the maintenance of market access. FHS can help to determine the distribution of alien pests already established in Australia (Wylie et al., 2008), which is necessary to determine whether any new alien pests detected post-border are worth considering for eradication. Baseline data on established alien pests may also assist with predicting taxa that may be future invasive threats (Nahrung and Carnegie, 2020, Nahrung and Carnegie, in prep). While FHS is not efficient at early detection of new alien pest incursions (Wardlaw et al., 2008), new alien pests are regularly detected. More than one third of alien pests detected in Australia over the past three decades were found through FHS or surveillance by industry staff (Carnegie and Nahrung, 2019; Trollip et al., 2021), highlighting the benefits of FHS in an overall forest biosecurity program.

Despite these efforts to bolster post-border surveillance for alien forest pests, the approach remains ad hoc, and is not coordinated nationally or well-integrated with national or state biosecurity activities (Carnegie et al., 2017, 2018a; Tovar et al., 2017; Department of Agriculture and Water Resources, 2018a,b). Surveillance efforts are constrained by fluctuating levels of funding from government and the forest sector, and relies heavily on a small number of state-based forest health experts (Mohammed et al., 2011; Tovar et al., 2017). It is recognized by government and industry that there is a need for a structured national forest pest surveillance program for early detection of alien forest pests. 


\section{A National Forest Pest Surveillance Program}

The recognition of lack of consistent and systematic forest pest surveillance activities nationally led to development of the Framework for Surveillance of Exotic Forest Pests (Tovar et al., 2017) and subsequently a National Forest Biosecurity Surveillance Strategy and its accompanying Implementation Plan (Department of Agriculture and Water Resources, 2018a,b). The strategy was designed with input from forest growers, forest health and biosecurity experts and state and national government agencies. A key output of the strategy is the establishment of the National Forest Pest Surveillance Program (NFPSP) to enable early detection of alien forest pests, thereby improving the chances of successful eradication (Department of Agriculture and Water Resources, 2018a). Its key pillars include high-risk site (active) surveillance by technical experts and general (passive) surveillance through stakeholder engagement. The proposed NFPSP is designed to be risk-based, with resources allocated to areas of highest risk for alien forest pest entry, and link seamlessly with the broader plant biosecurity surveillance system and forest sector FHS programs (Figure 1).

The NFPSP comprises five key components. A steering group and national coordinator will ensure program oversight and coordination while maintaining linkages with other national programs (e.g., NBS, NPHSP, forest sector FHS). Pathway risk analysis will be used to prioritize high-risk sites to target surveillance activities for both active surveillance (HRSS) and passive (stakeholder) surveillance. High-risk site (active) surveillance will be conducted by technical experts, and general (passive) surveillance via stakeholder engagement and training. Information technology infrastructure and tools will be developed to enable surveillance activities and reporting. These are elaborated below.

\section{Governance and Coordination}

A National Forest Biosecurity Steering Group (NFBSG) composed of representatives of major stakeholders (national and state governments and industry) and other invited representatives will oversee the activities of the NFPSP. A National Forest Biosecurity Coordinator (NFBC), appointed by the forest industry, will coordinate and administer activities of the NFPSP. PHA, with broad stakeholder networks across government and plant industries, currently hosts this coordination role.

The diversity of hosts and environments that forest pests can invade requires collaboration from a broad set of stakeholders (Magarey et al., 2009). An innovative aspect of the proposed NFPSP is that its governance model includes a broad set of stakeholders (e.g., community and environment groups) in addition to those funding the activities. This is in recognition that not all stakeholders have the capacity to provide funding but may contribute to the NFPSP through provision of in-kind surveillance and/or pest reporting, especially in urban and periurban environments. For government and the forest sector it enables collaboration with other stakeholders that substantially expands the capacity for surveillance in urban areas.
A partnership between the forest sector and relevant national and state agencies to underpin the proposed NFPSP is being negotiated through 2021. The partnership will define the roles and responsibilities of the NFPSP partners as well as the program's governance, financial and operating arrangements. Current iterations of the partnership outline funding arrangements wherein the forest sector would contribute through a proposed $\$ 0.045 / \mathrm{m}^{3}$ increase to PHA's productionbased biosecurity levy (Australian Forest Products Association, 2021), the national government would contribute through provision of risk analysis services, and state governments would contribute through expertise and services in surveillance and diagnostics. The forest sector is indicating willingness to fund more than $70 \%$ of the proposed activities of the NFPSP, illustrating their commitment to improving forest biosecurity in Australia. The proposed NFPSP aims to begin in 2022 .

Formalization of a partnership between governments and the forest sector represents an effort to move away from project-based funding and to establish sustainable and equitable funding arrangements that enable ongoing surveillance activities to be supported across the major beneficiaries of alien forest pest biosecurity. It will establish the first formalized national biosecurity surveillance program outside of an emergency plant pest response situation that involves governments and a plant industry. Over the longer term, as pest risk pathways into Australia are better understood, contributions toward the NFPSP may be sought, where appropriate, from other plant industries (e.g., horticulture), other forest/tree beneficiaries (e.g., local governments) or risk creators (e.g., tourism industry).

The NFPSP priority pest list for surveillance activities will be developed through expert and stakeholder consultation from existing national, state and industry pest prioritization and risk assessment processes, including the National Priority Plant Pests list, ${ }^{3}$ the National Priority List of Exotic Environmental Pests, Weeds and Diseases, ${ }^{4}$ and the Plantation Forests Biosecurity Plan (Plant Health Australia, 2021).

\section{Pathway Risk Analysis}

Broad pest risk assessments are conducted by the Australian Government at a national level for multiple plant industries as well as environmental and amenity threats. The NFPSP will support specific pathway risk modeling and expert elicitation to prioritize areas where surveillance for alien forest pests should be focused. Areas of highest risk are generally considered to include areas surrounding major ports-of-entry (seaports, airports), and concentrations of quarantine-approved facilities where imported goods are held (Wylie et al., 2008). Expert elicitation and a recently developed pathways risk model [the Spatial Pest Entry Analysis Runner (SPEAR)] will be used to identify those highrisk areas. SPEAR is a Bayesian risk model that combines multiple factors such as pest biology, pathway information (e.g., type and volume of commodity), climate and host availability to assess the relative risk of alien pest entry and establishment in a systematic and standardized way (Mascaro and Woodberry, 2020). The outputs of the model are maps and ranked probability tables for

\footnotetext{
${ }^{3}$ www.agriculture.gov.au/pests-diseases-weeds/plant

${ }^{4}$ www.agriculture.gov.au/biosecurity/environmental/priority-list
} 
areas across Australia at configurable spatial scales showing the relative risk of alien forest pest entry between different regions. Thus, areas of highest risk-across Australia and within each state-can be identified and surveillance activities (i.e., HRSS, stakeholder engagement) are resourced accordingly.

\section{High-Risk Site Surveillance}

HRSS is a key component of the NFPSP. HRSS involves specific (active) surveillance for target alien pests undertaken at sites deemed high-risk for entry and establishment of the pest (Wylie et al., 2008; Carnegie et al., 2018a). HRSS is undertaken by technical experts and involves establishing insect traps (using pheromones or kairomones) for early detection of alien pests as well as host-tree surveillance (i.e., visual assessments) for detection of symptoms of alien pests. Highrisk areas identified through pathway risk analysis are explored for appropriate locations to establish traps and host-tree surveillance-commonly green spaces with high numbers of host trees. HRSS is intensive and therefore requires a lot of resources. To date, few alien pests have been detected by this method in Australia (Carnegie and Nahrung, 2019), noting, though, that it has not been consistently or comprehensively used throughout Australia.

\section{Stakeholder Surveillance}

It is well recognized that general (passive) surveillance is very effective at detecting alien species (Carnegie and Nahrung, 2019; Pawson et al., 2020; Epanchin-Niell et al., 2021); it is more extensive and requires considerably less resources than HRSS. The NFPSP stakeholder surveillance component is designed to create a network of engaged collaborators from high-risk points of entry to surrounding urban high risk establishment areas, and then to peri-urban forests and plantations. The NFPSP would provide collaborators (e.g., arborists, local councils, community groups, forest industry) with the knowledge, tools and training to recognize and report any new and unusual symptoms or pests on trees, effectively providing more capacity and capability for alien forest pest surveillance (e.g., Botanic Gardens Biosecurity Network ${ }^{5}$ ). Training will focus on stakeholders such as local councils and arborists in areas of highest risk for alien pest entry in urban and peri-urban areas. This will build on current forest biosecurity stakeholder engagement programs developed in Victoria, New South Wales ${ }^{6}$ and Queensland. The NFPSP aims to balance the resource allocation and efficacy of active and passive surveillance efficiently. In recognition that many alien forest pests are first detected during FHS (Carnegie and Nahrung, 2019; Trollip et al., 2021), the NFPSP proposes to link with existing and future FHS programs in the plantation estate.

\section{Reporting and Data}

The NFPSP will develop infrastructure and tools that enable surveillance activities for both HRSS and stakeholder surveillance, including the use of digital surveillance reporting tools. This could include the development of cyberinfrastructure (Magarey et al., 2009) to connect governments, technical experts, industry, and other stakeholders to respond to current and future

\footnotetext{
${ }^{5}$ https://extensionaus.com.au/botanicgardensbiosecurity/home

${ }^{6}$ https://www.dpi.nsw.gov.au/forestry/science/forest-health
}

biosecurity threats effectively and efficiently. Data collected through these tools will be collated through PHA's national surveillance data aggregator AUSPestCheck. ${ }^{7}$ PHA will work with the partners to develop the data requirements for the NFPSP and facilitate data sharing. While FHS of forest estates will still be an industry responsibility, the NFPSP will assist with collation of forest health datasets into regional and national datasets to support any pest-area-freedom claims and provide evidence that supports market access for Australian wood products.

\section{CONCLUSION}

The proposed NFPSP represents the culmination of years of research and representation by forest health experts in Australia going back to the 1990s. When implemented it will provide the basis for ongoing sustainable cooperation between governments and the forest sector to mitigate alien forest pest risk, improve their early detection and increase the chances of successful eradications. The exclusion of major alien forest pests from Australia is a shared national benefit. Key pillars of the proposed program include risk-based surveillance for early detection to increase eradication opportunities, and synergies between active (HRSS) and passive (stakeholder) surveillance in urban and periurban areas and with forest sector FHS to maximize surveillance effort across exotic pest entry pathways. The governance structure ensures strong linkages with other plant biosecurity surveillance programs in Australia, as well as ongoing pathway risk analysis through national collaboration. The NFPSP is unique in that it has been jointly driven and developed by the forest sector and the Australian Government-in recognition of the broader benefits for environmental and amenity forests-but will be funded mostly by the forest industry.

Design of the NFPSP is modeled on programs in New Zealand and the United States, who both have successful long-term biosecurity surveillance programs for early detection of alien forest pests. In New Zealand, formal, structured surveillance for alien forest pests around ports and high-risk sites began in the late 1980s (Carter, 1989; Kershaw, 1989; Bulman, 2008). Locations for surveillance are determined based on perceived risk of entry of alien pests, including sea and airports, and industrial sites where imported material is received. Visual inspections are made of trees in parks, reserves and roadsides; insect trapping is not routinely conducted. A review in 1999 recognized a need for wider stakeholder engagement to enhance general surveillance (Hosking et al., 1999), and several further reviews have identified risk sites based on changing risk pathways and refined surveillance methodology to improve detection (Bulman, 2008). HRSS in New Zealand is funded by the government and focuses on surveys of a broad suite of arborescent species, ${ }^{8}$ while the forest sector funds a separate but inter-linked Forest Biosecurity Surveillance program in the plantation estate. ${ }^{9}$ In the

\footnotetext{
${ }^{7}$ www.planthealthaustralia.com.au/resources/auspestcheck/

${ }^{8}$ https://www.mpi.govt.nz/biosecurity/how-to-find-report-and-prevent-pestsand-diseases/surveillance-programmes/

${ }^{9}$ https://www.nzffa.org.nz/farm-forestry-model/the- essentials/forest-healthpests-and-diseases/biosecurity/forestry-biosecurity-surveillance-in-newzealand/
} 
United States, pathway risk analysis is conducted to identify and prioritize high-risk sites as part of the Cooperative Agriculture Pest Survey (CAPS) for early detection of alien plant pests during post-border surveillance (Magarey et al., 2009). The CAPS program is similar to Australia's NPHSP in that it focuses on agricultural pests, but differs in that it includes a broad range of alien forest pests in its National Priority Pest List. ${ }^{10}$ Surveillance at high-risk sites includes visual inspection of host trees and insect trapping. The CAPS program utilizes expertise from federal and state agencies, universities and industry.

The NFPSP outlined in this paper will address many but not all the issues highlighted in previous audits and reviews (Mohammed et al., 2011; Carnegie et al., 2017; Tovar et al., 2017). For example, the maintenance of surveillance and diagnostic expertise specific to forest pests can only be partially addressed by the program through professional development training (Department of Agriculture and Water Resources, 2018a,b). It will also require long-term strategic investment from the forest sector and government in personnel with the required skill sets and for Australian universities and technical colleges to continue to provide appropriate courses in entomology and plant pathology. Further issues to be addressed include assessing social license for response and eradication activities such as tree removal (Carnegie et al., 2019; Carnegie and Nahrung, 2019), refining pest risk prioritization and assessment methods (Nahrung and Carnegie, in prep), and resolving the biosecurity responsibilities and arrangements for

\footnotetext{
${ }^{10} \mathrm{http}: / /$ pest.ceris.purdue.edu/services/napisquery/query.php?code=
} approvedmethods 2022

\section{REFERENCES}

ABARES (2016). Australian forest and wood products statistics: March, June, September, December quarters 2015. Canberra: Australian Bureau of Agricultural and Resource Economics and Sciences.

ABARES (2017). Agricultural commodity statistics 2017. Canberra: Australian Bureau of Agricultural and Resource Economics and Sciences.

Agriculture Victoria (2021). Giant pine scale. Melbourne: Agriculture Victoria.

Australian Forest Products Association (2021). Proposal to amend the forest grower levy. Canberra: Australian Forest Products Association.

Australian Government (2015). Biosecurity Act 2015. No. 165, 2015. Canberra: Commonwealth of Australia.

Bailey, P. (2012). Forest Biosecurity \& Preparedness Investment Plan. Melbourne: Forest and Wood Products Australia.

Bashford, R. (2003). The use of static traps for the detection and monitoring of exotic forest insects. Melbourne: J.W. Gottstein Memorial Trust Fund.

Bashford, R. (2012). "The development of a port surrounds trapping system for the detection of exotic forest insect pests in Australia," in New Advances and Contributions to Forestry Research, ed. A. A. Oteng-Amoako (London: InTech), doi: 10.5772/35068

Beale, R., Fairbrother, J., Inglis, A., and Trebeck, D. (2008). One Biosecurity: a working partnership. The independent review of Australia's quarantine and biosecurity arrangements report to the Australian Government. Canberra: Commonwealth of Australia.

Bennett, S. (2020). Open Trees Database. Available online at: http://opentrees.org/ \#pos=1/-37.8/145 (accessed October 1, 2021).

Branco, M., Nunes, P., Roques, A., Fernandes, M. R., Orazio, C., and Jactel, H. (2019). Urban trees facilitate the establishment of non-native forest insects. NeoBiota 52, 25-46. doi: 10.3389/fphys.2019.00550

Bulman, L. S. (2008). Pest detection surveys on high-risk sites in New Zealand. Aust. For. 71, 242-244. doi: 10.1080/00049158.2008.10675042 timber-in-service pests, which are not clearly covered under EPPRD or NEBRA (Horwood et al., in prep).

\section{AUTHOR CONTRIBUTIONS}

AC conceived the manuscript. AC and FT wrote the initial draft. All authors revised the final manuscript.

\section{FUNDING}

HN funded through an Advance Queensland Industry Fellowship-Queensland Department of Innovation and Tourism Industry Development, supported by the University of the Sunshine Coast, Department of Agriculture, and Fisheries, National Sirex Coordination Committee, Forest and Wood Products Australia, Plant Health Australia, and HQPlantations Pty Ltd.

\section{ACKNOWLEDGMENTS}

We thank all those forest health technical experts who started this journey three decades ago. We thank Ranjith Subasinghe for critically reviewing an earlier draft of the manuscript and detailed comments from the two reviewers which improved the manuscript.

Burley, H., Beaumont, L. J., Ossola, A., Baumgartner, J. B., Gallagher, R., Laffan, S., et al. (2019). Substantial declines in urban tree habitat predicted under climate change. Sci. Total Env. 685, 451-462. doi: 10.1016/j.scitotenv.2019.05. 287

Cahill, D. M., Rookes, J. E., Wilson, B. A., Gibson, L., and McDougall, K. L. (2008). Phytophthora cinnamomi and Australia's biodiversity: impacts, predictions and progress towards control. Aust. J. Bot. 56, 279-310. doi: 10.1071/BT0 7159

Cameron, N. L., Carnegie, A. J., Wardlaw, T., Lawson, S., and Venn, T. (2018). Economic appraisal of Sirex Wood Wasp (Sirex noctilio) control in Australian pine plantations. Aust. For. 81, 37-45. doi: 10.1080/00049158.2018.14 30436

Carnegie, A. J, Lawson, S., Wardlaw, T., Cameron, N., and Venn, T. (2018a). Benchmarking forest health surveillance and biosecurity activities for managing Australia's exotic forest pest and pathogen risks. Aust. For. 81, 14-23. doi: 10.1080/00049158.2018.1433271

Carnegie, A. J., Venn, T., Lawson, S., Nagel, M., Wardlaw, T., Cameron, N., et al. (2018b). An analysis of pest risk and potential economic impact of pine wilt disease to Pinus plantations in Australia. Aust. For. 81, 24-36. doi: 10.1080/ 00049158.2018.1440467

Carnegie, A. J., Nagel, M., and Sargeant, D. (2018c). Review of current biosecurity surveillance activities targeting high priority forest pests. Sydney: NSW Department of Primary Industries.

Carnegie, A. J., Lawson, S., Cameron, N., Wardlaw, T., and Venn, T. (2017). Evaluating the costs and benefits of managing new and existing biosecurity threats to Australia's plantation industry. Melbourne: Forest and Wood Products Australia.

Carnegie, A. J., Lidbetter, J. R., Walker, J., Horwood, M. A., Tesoriero, L., Glen, M., et al. (2010). Uredo rangelii, a taxon in the guava rust complex, newly recorded on Myrtaceae in Australia. Austral. Plant Pathol. 39, 463-466. doi: 10.1071/AP10102 
Carnegie, A. J., and Nahrung, H. F. (2019). Post-border forest biosecurity in Australia: response to recent exotic detections, current surveillance and ongoing needs. Forests 10:336. doi: 10.3390/f10040336

Carnegie, A. J., O’Gara, E. O., Makinson, R. O., Hardy, G. E. StJ. (2021). Global plant Health Assessment: Australian Eucalypt Forests. Unpublished. International Society for Plant Pathology, Global Plant Health Assessment. Available online at: https://sites.google.com/view/global-plant-healthassessment/home

Carnegie, A. J., and Pegg, G. S. (2018). Lessons from the incursion of myrtle rust in Australia. Annu. Rev. Phytopathol. 56, 457-478. doi: 10.1146/annurev-phyto080516-035256

Carnegie, A. J., Tovar, F., Elms, S., Smith, D., Moore, A., Aurik, D., et al. (2019). Giant pine scale emergency response industry review. Canberra: Australian Forest Products Association.

Carter, P. C. S. (1989). Risk assessment and pest detection surveys for exotic pests and diseases which threaten commercial forestry in New Zealand. New Zealand J. Forest. Sci. 19, 353-374.

Commonwealth of Australia (2021). Commonwealth Biosecurity 2030. Canberra: Department of Agriculture, Water and the Environment.

Council of Australian Governments (2019). Intergovernmental Agreement on Biosecurity. Canberra: Council of Australian Governments.

Craik, W., Palmer, D., and Sheldrake, R. (2017). Priorities for Australia's biosecurity system - An independent review of the capacity of the national biosecurity system and its underpinning Intergovernmental Agreement. Canberra: Commonwealth of Australia.

Department of Agriculture \& Department of Environment (2014). Joint Submission, Inquiry into environmental biosecurity. Canberra: Standing Committee on Environment and Communications References Committee.

Department of Agriculture and Water Resources (2018a). National forest biosecurity surveillance strategy 2018-2023. Canberra: Plant Health Australia.

Department of Agriculture and Water Resources (2018b). National forest biosecurity surveillance strategy: implementation plan 2018-2023. Canberra: Plant Health Australia.

Dodd, A., Stoeckl, N., Baumgartner, J., and Kompas, T. (2020). Key result summary: valuing Australia's biosecurity System. Melbourne: CEBRA.

Dyck, W., and Hickling, G. (2021). Plant biosecurity science in New Zealand: Gaps in capability and capacity to avoid or mitigate serious pest and pathogen incursions. LC3902. Lincoln: Landcare Research.

Epanchin-Niell, R., Thompson, A. L., and Treakle, T. (2021). Public contributions to early detection of new invasive pests. Conserv. Sci. Pract. 3:e422. doi: 10.1111/ $\operatorname{csp} 2.422$

FAO (2016). Guidelines on urban and peri-urban forestry, by F. Salbitano, S. Borelli, M. Conigliaro and Y. Chen. FAO Forestry Paper No. 178. Rome: Food and Agriculture Organization of the United Nations.

Horwood, M., Lawson, S., Nahrung, H., Tovar, F., and Carnegie, A. J. (in prep). The Threat of Timber in Service Pests to Australian Forestry.

Hosking, G. P., Bulman, L., Bradbury, P., Barr, C., and Rogan, B. (1999). Hazard site review. Unpublished report for the Chief Forestry Officer. Wellington: Ministry of Agriculture and Forestry.

Inspector-General of Biosecurity (2019a). Environmental biosecurity risk management in Australia. Canberra: Department of Agriculture and Water Resources.

Inspector-General of Biosecurity (2019b). Pest and disease interceptions and incursions in Australia. Canberra: Department of Agriculture and Water Resources.

Kershaw, D. J. (1989). History of forest health surveillance in New Zealand. New Zealand J. Forest. Sci. 19, 375-377.

Lawson, S. A., Carnegie, A. J., Cameron, N., Wardlaw, T., and Venn, T. J. (2018). Risk of exotic pests to the Australian forest industry. Aust. For. 81, 3-13. doi: 10.1080/00049158.2018.1433119

Magarey, R. D., Colunga-Garcia, M., and Fieselmann, D. A. (2009). Plant biosecurity in the united states: roles, responsibilities and information needs. BioScience 59, 875-884. doi: 10.1525/bio.2009.59.10.9

Mansfield, S., McNeill, M. R., Aalders, L. T., Bell, N. L., Kean, J. M., Barratt, B. I., et al. (2019). The value of sentinel plants for risk assessment and surveillance to support biosecurity. NeoBiota 48, 1-24. doi: 10.3897/neobiota.48. 34205

Mascaro, S., and Woodberry, O. (2020). Establishing a National Forest Biosecurity Surveillance Program PIN 27399 - Forest Pest Pathways Analysis Final Report. Canberra: Department of Agriculture and Water Resources.

Mohammed, C., Glen, M., Walshe, T., Wardlaw, T., Stone, C., Beadle, C., et al. (2011). An audit of forest biosecurity arrangements and preparedness in Australia. Melbourne: Forest and Wood Products Australia.

Montreal Process Implementation Group for Australia and National Forest Inventory Steering Committee (2018). Australia's state of the forests report 2018: five-yearly report. Canberra: ABARES.

Nahrung, H. F., and Carnegie, A. J. (2020). Non-native forest insects and pathogens in Australia: establishment, spread, and impact. Front. Forest. Glob. Chang. 3:37. doi: $10.3389 /$ ffgc. 2020.00037

Nahrung, H. F., and Carnegie, A. J. (in prep). Predicting Forest Pest Threats in Australia: Are Risk Lists Worth the Paper They're Written On?

Nairn, M. E., Allen, P. G., Inglis, A. R., and Tanner, C. (1996). Australian quarantine: a shared responsibility. Canberra: Department of Primary Industries and Energy.

Paap, T., Burgess, T. I., and Wingfield, M. J. (2017). Urban trees: bridge-heads for forest pest invasions and sentinels for early detection. Biolog. Invas. 19, 3515-3526. doi: 10.1007/s10530-017-1595-x

Pawson, S. M., Sullivan, J. J., and Grant, A. (2020). Expanding general surveillance of invasive species by integrating citizens as both observers and identifiers. J. Pest Sci. 93, 1155-1166. doi: 10.1007/s10340-020-01259-x

Plant Health Australia (2007). Plantation Forest Biosecurity Plan (Version 1.0). Canberra: Plant Health Australia.

Plant Health Australia (2010). National Plant Biosecurity Strategy. Canberra: Plant Health Australia.

Plant Health Australia (2013). Plantation Forest Biosecurity Plan (Version 2.0). Canberra: Plant Health Australia.

Plant Health Australia (2015). Biosecurity Manual for Plantation Timber Industry. Version 1.0. Canberra: Plant Health Australia.

Plant Health Australia (2019a). 2019 National Plant Biosecurity Status Report. Canberra: Plant Health Australia.

Plant Health Australia (2019b). PLANTPLAN: Australian Emergency Plant Pest Response Plan. Version 3.3. Canberra: Plant Health Australia.

Plant Health Australia (2020). Government and Plant Industry Cost Sharing Deed in respect of Emergency Plant Pest Responses. Canberra: Plant Health Australia.

Plant Health Australia (2021). Plantation Forest Biosecurity Plan (Version 3.0). Canberra: Plant Health Australia.

Smith, D., Smith, B., and Smith, I. (2010). The use of sentinel plantings to provide an early warning of potential pests of concern to the Victorian timber industry. Melbourne: Agriculture Victoria.

Tovar, F., Carnegie, A., Collins, S., Horwood, M., Lawson, S., and Smith, D. (2017). Framework for surveillance of exotic forest pests. Canberra: Plant Health Australia.

Trollip, C., Carnegie, A. J., Dinh, Q., Kaur, J., Smith, D., Mann, R., et al. (2021). Ophiostomatoid fungi associated with pine bark beetles and infested pines in south-eastern Australia, including Graphilbum ipis-grandicollis sp. nov. IMA Fungus 12:24. doi: 10.1186/s43008-021-00076-w

Wardlaw, T. J., Bashford, R., Wotherspoon, K. P., Wylie, F. R., and Elliott, H. J. (2008). Efficiency of routine forest health surveillance in detecting pest and disease damage in eucalypt plantations. New Zealand J. Forest. Sci. 38, 253-269.

Wylie, F. R., Griffiths, M., and King, J. (2008). Development of hazard site surveillance programs for forest invasive species: a case study from Brisbane. Austral. Austral. Forest. 71, 229-235. doi: 10.1080/00049158.2008.1067 5040

Conflict of Interest: AC, FT, SL, and SC were involved in developing the Framework for surveillance of exotic forest pests and the National forest biosecurity surveillance strategy and implementation plan. Both documents were 
funded by DAWE and PHA, who employ SC and FT, respectively. FT was the National Forest Biosecurity Coordinator.

The remaining author declares that the research was conducted in the absence of any commercial or financial relationships that could be construed as a potential conflict of interest.

Publisher's Note: All claims expressed in this article are solely those of the authors and do not necessarily represent those of their affiliated organizations, or those of the publisher, the editors and the reviewers. Any product that may be evaluated in this article, or claim that may be made by its manufacturer, is not guaranteed or endorsed by the publisher.

Copyright (C) 2022 Carnegie, Tovar, Collins, Lawson and Nahrung. This is an openaccess article distributed under the terms of the Creative Commons Attribution License (CC BY). The use, distribution or reproduction in other forums is permitted, provided the original author(s) and the copyright owner(s) are credited and that the original publication in this journal is cited, in accordance with accepted academic practice. No use, distribution or reproduction is permitted which does not comply with these terms. 